\title{
START A REVOLUTION IN YOUR HEAD! THE REBIRTH OF ICT ETHICS EDUCATION
}

\author{
Simon Rogerson \\ Centre for Computing \& Social Responsibility, De Montfort University (UK) \\ srog@dmu.ac.uk
}

\begin{abstract}
This paper is a viewpoint rather than grounded in research. It questions some of the established ICT norms and traditions which exist both in industry and academia. The aim is to review current ICT ethics educational strategy and suggest a repositioning which aligns with the concept of computing by everyone for everyone. Professional bodies, in their current role, have little influence on 97 percent of global software developers whose ethical code and attitude to social responsibility comes from elsewhere. There needs to be a radical change in how the ethical and social responsibility dimension of ICT is included in education of the whole population rather than focusing on the elitist computing professional community. It is against this backdrop that this paper explores new avenues for widening education, both formal and informal, to all those who may become involved in computing. The discussion concludes by laying out a new pathway for ICT ethics education which embraces people of all ages and all walks of life.
\end{abstract}

KEYWORDS: Thought Experiment, STEM, STEAM, Poetry, ICT Ethics, Oral History.

\section{INTRODUCTION}

Computing is no longer the sole domain of professionals, educated and trained through traditional routes to service public and private sector organisations under paid contracts. Computing is now by everyone for everyone with the advent of economically accessible hardware, a multitude of software tools and the Internet (Rogerson, 2019a). The IDC survey of 2018 found that there were, worldwide, $18,000,000$ professional software developers and 4,300,000 additional hobbyists. The combined membership of leading professional bodies, ACM, ACS, BCS and IFIP represents only 3.09 per cent of that global total. The youngest app developer at Apple's Worldwide Developers Conference in June 2019 was Ayush Kumar aged 10 who started coding when he was 4 years old (Graham, 2019). He is not alone, 15 year old, Tanmay Bakshi, who is the world's youngest IBM Watson Developer, started software development when he was 5 years old (Param, 2018). These facts suggest that professional bodies, in their current role, have little influence on 97 percent of global software developers whose ethical code and attitude to social responsibility comes from elsewhere.

It is now over a year since the launch of the new code of ethics for the ACM. At the last ETHICOMP conference much time was devoted to discussing the Code and the part it would play in moving ICT ethics forward. The code has spawned the ACM Integrity Project: Promoting Ethics in the Profession (https://ethics.acm.org/integrity-project/). The aim of this 2-year project of the ACM Committee on Professional Ethics is to promote ethics in the profession though modern media: YouTube videos, podcasts, social media, and streaming video. The use of modern media should certainly appeal to post 
millennials and offers a new approach to engage with future generations of computer scientists. Unfortunately, there has been little exposure of this project in, for example, the ACM's flagship publication, the Communications of the ACM. However, that same publication ran as its cover story in the August 2019 edition "Embedded EthiCS: integrating ethics across CS education" (Grosz et al, 2019). This is a paper about Harvard reinventing the wheel of computer ethics education which has a long and comprehensive history stretching back to the 1980s (see, for example, Aiken, 1983, Johnson, 1985, and Miller, 1988). It offers little new insight, does not link to a 40 year history and experience (for example see Pecorino and Maner, 1985; Martin, Huff, Gotterbarn and Miller, 1996; and Bynum and Rogerson 2004), nor does it appear to connect with the Integrity Project.

Within industry and government, the compliance culture has taken a firm hold and so strangles the opportunity for dialogue and analysis of complex multi-faceted socio-ethical issues related to ICT. Superficial compliance is dangerously unethical and must be challenged vigorously in a technologicallydependent world. The timeframes for ICT development and ICT regulation and governance are, and will always be, misaligned. By the time some control mechanism is agreed, the technology will have moved on several generations and thus what has been agreed is likely to be ineffective. Currently, this seems to be the case with the governance of Artificial Intelligence, as there are so many opinions and vested interests causing protracted debate whilst AI marches onwards. Thus, it is paramount to imbue strategists, developers, operators and users with practical ICT ethics. In this way ethical computing has a chance of becoming the norm. Traditional approaches of professional bodies seem ineffective in a society which is moving rapidly towards complete dependency on technology

It is this landscape which makes the ETHICOMP 2020 theme, Paradigm shifts in ICT Ethics, so relevant. It is time to change. In the spirit of Kuhn (1962) we need a paradigm shift in ICT Ethics to address the societal challenges in the not-so-smart society of today. He suggests that scientific progress of any discipline has three phases: pre-paradigm phase, a normal phase and a revolution phase. Progress occurs when a revolution takes place after a dormant normal period and the community moves ahead to a paradigm shift. Given the ongoing frequent occurrence of ICT disasters, it seems ICT ethics education in its current dormant normal phase is in need of revolution. There needs to be a radical change in how the ethical and social responsibility dimension of ICT is included in education of the whole population rather than focusing on the elitist computing professional community. It is against this backdrop that this viewpoint explores four new avenues for widening education, both formal and informal, to all those who may become involved in computing. These avenues are: science and technology museums, history, thought experiments, and poetry. Such avenues also offer greater awareness to the public at large and align with Burton et al (2018), who use science fiction to teach ICT ethics, rather than Harvard's unimaginative, traditional approach already discussed.

\section{AVENUE ONE: SCIENCE AND TECHNOLOGY MUSEUMS}

An innovative interactive facility, Ethical Technology could be rolled out across the global network of science and technology museums and activity centres. It would be a programme for children and adults of all ages. It would be the catalyst for public awareness and public voice, schools' cross curricular

activities, higher education research, teaching and learning, and new meaningful purpose for professional bodies.

Ethical Technology comprises four elements: If by chance, Story time, Worldwide watch and Out and about which combine to form a compound view of the ethical dimension of computing technologies and the ramifications for general population. 
The first element, If by chance, is an opportunity to see giants of computing and literature in a different light through a set of hypothetical conversations between contemporary pairs. The conversation is on an ethical technology topic which is relevant to the expertise, experience and thinking of the pair of individuals. For example, Charles Babbage and Ada Lovelace discuss the increasing use of moral algorithms in everyday technology. The moral algorithm is used to embed ethical decision making into, for example, driverless cars. In a second example, Isaac Asimov and an intelligent robot discuss the relationship between human and android. Global laws and legal frameworks provide the scaffolding for a civilised society. How do The Three Laws of Robotics and android rights impact on a human society?

The second element, Story time, is a series of case scenarios which contain at least one ethical dilemma. Every story is based on either a real event or created by combining existing technologies in a societally-damaging manner. A typical example is this hypothetical story, The Data Shadow, about personal data which resides on the internet. It has its foundation in things which have happened (Rogerson,2017). It raises serious questions about whether we should be more aware of the risks associated with data shadows and whether there are things organisations and individuals could do to reduce such risks. The person engaging with the story is given a range of options to choose from to resolve the dilemma. The likely outcome of a chosen option is displayed. An infograph displays the totals of each option chosen with a summary of the likely outcomes for each.

The third element, Worldwide watch, is a repository of ethical and unethical technology occurrences. This element is an interactive blog which tracks worldwide media to collect stories of unethical and ethical technology. People will be able to give their opinions via a simple Likert scale for ethics. This could be part of a web-based offering where people could also add comments. In this way a rich dynamic record of ethical technology issues could be captured and retained. Again total opinions are captured using an infograph. This element offers an online link to be established across the participating community.

The fourth and final element, Out and about, is the outreach element of Ethical Technology. Much of the technology which pervades living space is ethically and socially sensitive. Such commonplace technology becomes invisible and unsurprising. Out and about aims to increase public awareness by providing multimedia information about technology and the associated ethical and societal sensitivity. Access could be, for example, through a QR reader on a smart phone. This element links people to Ethical Technology in their living space. Computer-based technology in everyday use in public spaces is used to illustrate the associated ethical and social issues. In this way public awareness is increased resulting in greater community questioning and calls for justified accountability. The applications such as ATMs, CCTV, and contactless payment systems would be fitted with QR codes which provide links to multimedia information about the ethical and social dimensions. Using this element, virtual assistants, such as Alexa and Siri, which masquerade as pseudo-friends, could be ethically contextualised.

\section{AVENUE TWO: LEARNING FROM HISTORY}

Deborah Johnson $(1997, \mathrm{p} 61)$ wrote "The ethical issues surrounding computers are new species of generic moral problems. This is as true when it comes to online communication as it is in any other area of computing. The generic problems involve privacy, property, drawing the line between individual freedom and (public and private) authority, respect, ascribing responsibility, and so on. When activities are mediated or implemented by computers, they have new features. The issues have a new twist that make them unusual, even though the core issue is not." She has been proved correct and consequently there is much to be learnt from the history of computers through, for example trade 
journal archives and the Communications of the ACM archive. However, in the context of ICT ethics the annals of ETHICOMP provide a particularly rich resource from which to learn. These historical records are important because history forces both scholar and practitioner "to lift their heads beyond the lab bench or the clipboard and realize the greater social, economic, and racial contexts in which their [work] plays out. It gives them a sensitivity that only the humanities can teach." (Dubcovsky, 2014). The themes of the first conference, ETHICOMP 95, were Ethical Development (The use of development methodologies and the consideration of ethical dilemmas, user education and professionalism); Ethical Technology (Advances in technologies and the ethical issues they are likely to raise when applied to business and social problems.); and .Ethical Applications (Developing ethical strategies which allow technology to be exploited in an ethically acceptable way.). This remains a relevant landscape and so illustrates that reflecting on the past can help in addressing the ICT ethical challenges of today and the future.

In its 25 years history ETHICOMP has evolved from a fledgling conference to become a multigenerational global community. Therefore the value of ETHICOMP is not simply the conference themes and associated papers but it is its community of people and their thoughts and observations over the passage of time. Such narrative is often forgotten or overlooked. Oral history addresses this oversight because it is a way of gathering, recording, and preserving a diverse range of personal experiences that generally are not well documented in written sources (Dalton, 2017). It enhances reflective thinking in both typical and non-typical educational settings (Gazi and Nakou, 2015). For this reason oral histories began being collected at ETHICOMP 2018. To date 18 have been collected involving around 25 people belonging to the ETHICOMP community. Summaries are being prepared so that easy access can be facilitated.

Currently there exists a comprehensive record of ETHICOMP (held by this author) which maps the complete history of the ETHICOMP conference series from the kernel of the idea through to the latest conference However, this collection is inaccessible and the potential value for future generations of scholars, practitioners and observers is lost. This archive comprises conference themes and calls; programmes; abstracts, proceedings, posters and flyers; pictures; videos; oral histories; and spin-off activities and miscellaneous materials. This could be housed on a purpose-built website to establish an interactive repository which not only holds the archive but also had a blog and social media facility which enables visitors to add content and make comment. This interactive repository using a chronological taxonomy would offer practical ethical insight to all those involved in computing. The Chronological Taxonomy is novel and potentially valuable across all empirical research disciplines (Rogerson, 2018). It is a two-dimensional method of ordering; the first dimension is Chronology which focuses on time and the second dimension is Taxonomy which focuses on classification. A typical classification could be based in IFIP's technical committees and working groups structure. The Chronological Taxonomy is a powerful tool which can be used to structure and analyse the interactive repository through using concatenated keys to sort the data thus making issues, trends and patterns more visible. As the data set held in the repository expands and perhaps automatic feeds are established to harvest advances and issues, the use of Big Data analytics might be needed.

\section{AVENUE THREE: THOUGHT EXPERIMENTS}

Brown and Fehige (2014) explain that thought experiments are used to investigate the nature of things through one's imagination. Usually they are communicated through narratives and accompanying diagrams. Brown and Fehige state that, "Thought experiments should be distinguished from thinking about experiments, from merely imagining any experiments to be conducted outside the imagination, and from psychological experiments with thoughts. They should also be distinguished from 
counterfactual reasoning in general, ...". This approach can be used to explore the possible dangers of dual use of technological advances that could occur in the absence of effective ethical scrutiny. Rogerson (2020a) uses two thought experiment instruments to acquire new knowledge about the dangers of Free and Open-Source Software (FOSS) components which could have dual usage in the context of a fictitious system, Open Genocide. It is an investigation which cannot use empirical data as this would require the actual and immoral construction of a system of annihilation.

These thought experiments are grounded in the Holocaust enacted by the Nazis. By the end of the war some 6 million Jews and many millions of Poles, gypsies, prisoners of war, homosexuals, mentally and physically handicapped individuals, and Jehovah's Witnesses had been murdered. The historical account of human suffering is sickeningly shocking but alongside this is the realisation of evil brilliance, not mindless thuggery, that orchestrated the Final Solution (a Nazi euphemism for the plan to exterminate the Jews of Europe).

On a bitterly cold day in February 2006 the author (SR) was quietly standing looking at the building which housed the gas chamber at Auschwitz. He reflected on the evil brilliance which had facilitated the Final Solution. He wondered what might have happened if the computer technology of 2006 had been available to the Nazis. It was a consideration which resonated with Would you sell a computer to Hitler by Nadel \& Wiener (1977). On returning home he completed the first thought experiment which was subsequently published (Rogerson 2006). Technological Determinism argues that technology is the force which shapes society. Computing power would therefore be a major force in activating the Final Solution. Value Chain Analysis (Porter, 1985) is one way to consider the impact of this force. Indeed Porter and Miller (1985, p151) wrote, "Information technology is permeating the value chain at every point, transforming the way value activities are performed and the nature of the linkages among them. ... information technology has acquired strategic significance and is different from the many other technologies businesses use." Many computer application systems that existed in 2006 and which were proven and accepted could have been used to realise the Final Solution. This is illustrated in Figure 1.

Figure 1. Indicative examples across the Final Solution Value Chain.

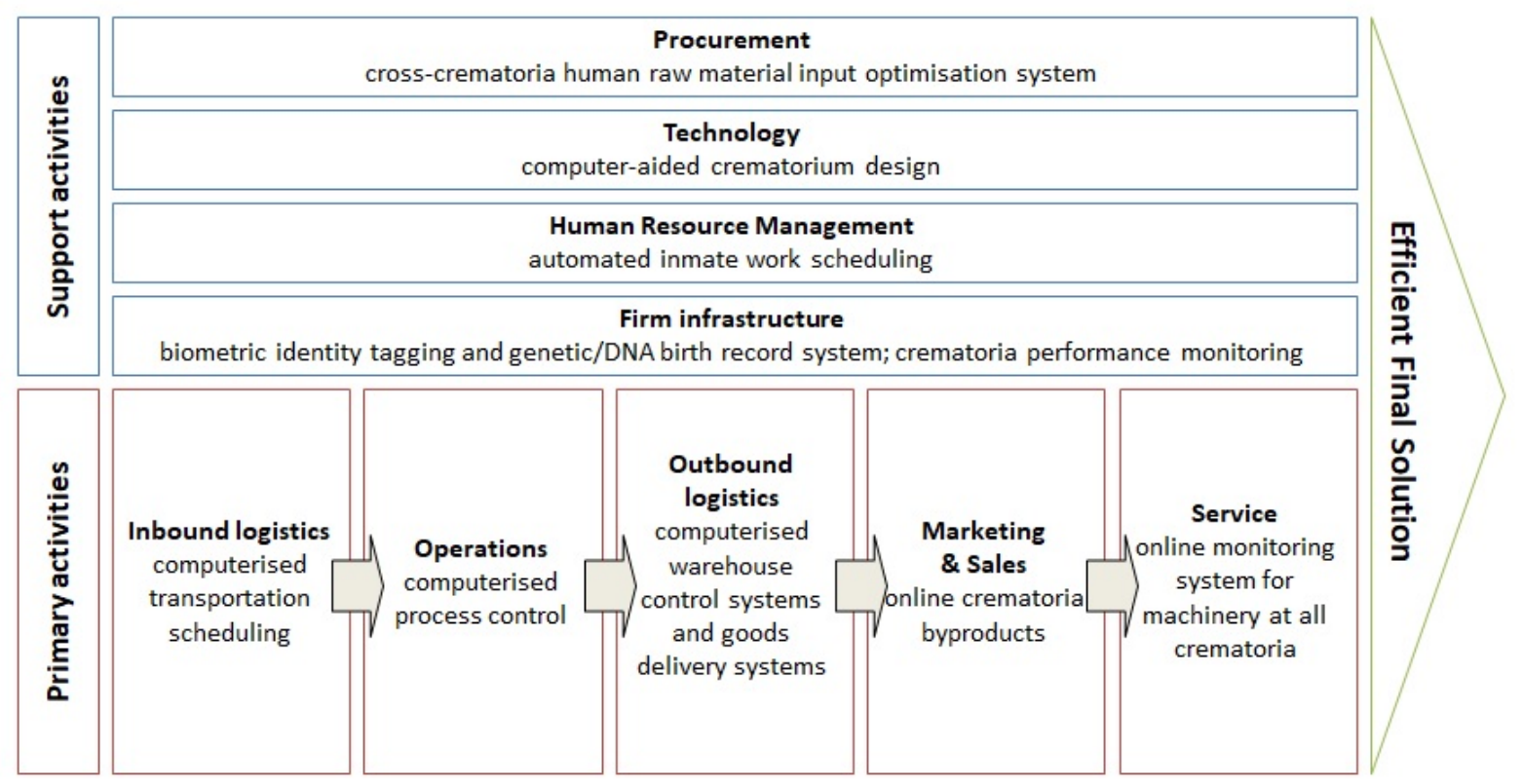


In 2018, 12 years later, the second thought experiment was undertaken. Technology has evolved at a seemingly increasing pace. Indeed, "In the not-too-distant future with the cloud, big data, and maybe $80 \%-90 \%$ of the world's population online and connected the scope for systems of oppression seems limitless. Consequently, we must consider and counter what oppressive regimes of tomorrow's world could and might do in their drive to subjugate humankind." (Rogerson, 2015, p4) Imagine a world where all software is available as free open source. It might seem improbable but it is possible. If it were so, the wherewithal to exploit every technological advance for any cause, albeit good or bad, would exist. The scene is set for an Open Genocide system brutally to further the cause of an extreme faction at the expense of the world at large and "destroy in whole or in part, a national, ethnical, racial or religious group" (United Nations, 1948, Article 2). Open Genocide would comprise seven components:

1. Identify: Systematically review the whole geographic region to identify every person within the targeted group as well as every sympathiser of this group.

2. Detain: Organise the detention of all identified persons in distributed holding pounds. Each detainee is appropriately tagged.

3. Deport: Manage the distribution and redistribution of detainees to work compounds and prisons.

4. Use: Select detainees exhibiting work value for allocation to appropriate tasks.

5. Dispose: Remove to disposal units all valueless or dead detainees thereby freeing up space in prisons and work compounds.

6. Recycle: Collect, sort, recycle and market all seized assets. Produce and market detainee byproducts.

7. Broadcast: Devise plausible propaganda for local and international audiences and communicate widely.

The pervasive nature of current computing technology facilitates all components of Open Genocide. A cursory inspection of two open source portals, SourceForge and The Black Duck Open Hub, reveals many useful items for the construction of Open Genocide.

These thought experiments might be shocking to many readers. That is their intention. It seems that if the Holocaust had occurred in our technologically-advanced modern world there is a very good chance that it would have completely succeeded. If ever there was an example to convince computing professionals, as custodians of the most powerful technology yet devised, of their responsibilities and obligations to humankind, this is it.

\section{AVENUE FOUR: POETRY}

There is value of linking the arts with the sciences in the delivery of ICT ethics education and poetry can serve as the vehicle (Rogerson, 2020b). Over 500 years ago, Leonardo da Vinci wrote that poetry is painting that is felt rather than seen. Such sentiment is echoed in "We can never learn too much about a poem, but always we come back to the work itself, for it exists not only as an historical object and the product of a particular mind and vision, but also in its own right, as an enduring work of art." (Anon, 1980). Poetry challenges us to think beyond the obvious and reflect on what has been, what is and what might be. Poetry can reboot the way in which social impact education is delivered to technologists. According to Rule et al (2004) incorporating poetry in science and technology teaching 
expands the curriculum beyond subject knowledge and process skills. They argue that images and metaphors in poems can clarify and intensify meaning. A poem has many layers and such richness can promote enlightenment and understanding. Poems can provide meaningful context. This is imperative in ICT education and awareness at all levels for all people as the social impact of technological advances is ever increasing. In partnership, computer science and liberal arts educators could offer an exciting new perspective through poetry as an instrument of presentation and discussion as well as in creative exercises for students.

Consider this example of using haikus. For readers who are unfamiliar with haikus, Trumbull (2003) explains that a haiku takes a three line format of 5-7-5 syllables known as a kigo and uses a cutting technique called kire to divide the verse into two parts for contrast or comparison. He argues that the more radical the verse the better the haiku. This is certainly the case when considering the broader issues surrounding the development and use of ICT.

Warning of technological advances without careful consideration beyond the technology is the focus of Machine - the final chapter (Rogerson, 2019b). Lack of proper checks and balances means that advances in computer technology from its inception by pioneers such as Babbage and Lovelace, through to the forefronts of artificial intelligence giving rise to ensuing disaster, potentially moving towards Armageddon as laid out in these three haikus.

\author{
Machine - the final chapter

\section{Computer} \\ Bits, bytes, ones, zeros \\ So Charles and Ada conceive - \\ IT's Pandora's box
}

\title{
Robot
}

Man and beast replaced

Same task over and over -

Objective carnage

Al

Boolean bible

Artificial ignorance -

Logical ending

\section{Armageddon!}

Poetry can be the key to unlock the door so the room can be explored. In the ICT setting this is important because often the most challenging ethical dilemmas are the least obvious. Different perspectives, for example, the poetical lens, can provide greater visibility.

\section{BEYOND STEM BOTH FORMALLY AND INFORMALLY}

ETHICOMP 2020's overarching theme of "Paradigm Shifts in ICT Ethics: Societal Challenges in the Smart Society" encourages its community to think beyond the obvious and traditional, and re-evaluate what 
should be done to ensure computing by everyone for everyone is ethically and societally acceptable. The four avenues discussed illustrate the way in which a paradigm shift might take place but for this to happen there needs to be an overarching framework to provide necessary scaffolding. A modification of the STEM model offers such a framework.

STEM has its roots in the US National Science Foundation and refers to teaching and learning in the fields of science, technology, engineering, and mathematics. It typically includes educational activities across all levels from pre-school to post-doctorate in both formal and informal settings. It requires the abandonment of top down approaches with teachers willing to talk to each other and to believe that interactions between subjects will result in enhanced learning opportunities (Williams, 2011). However, the problem with STEM is that it sustains the principle that there are two separate fundamental cultures; the scientific and the humanistic. This can restrict reflection and innovation. As Yakman $(2008, \mathrm{p} 19)$ states, "Trends have also shown many of the branches of the arts being more and more marginalized .... this is a tragedy, as it eliminates many primary ways for students to obtain contextual understanding." Indeed members of the ICT ethics community often encounter opposition from those who subscribe to this principle thus hampering the quest for ethical technology by design rather than by accident.

In 2006, Yakman conceived a model which blends STEM and the arts in a way which addresses this shortcoming. The STEAM Pyramid, as it is named and shown in Figure 2, aims, "...to correlate the subject areas to one another and the business and social development worlds ... [and] ... to create a matrix by which researchers, professionals, and educators could share information to keep education as up to date as possible while still having a basis in methodologies" (STEAM Pyramid History at http://steamedu.com/pyramidhistory/). Watson \& Watson (2013, p3) explain that "The arts contribute to STEM education by exposing students to a different way of seeing the world. Students learn through different pedagogical modalities engaging their other interests. By applying the STEM disciplines, combined with real-world experience, students become more comfortable in both worlds." In this holistic view the single discipline silos are augmented by a blended approach which better reflects the real world.

Figure 2. The STEAM approach as conceived by G. Yakman of STEAM Education in 2006.

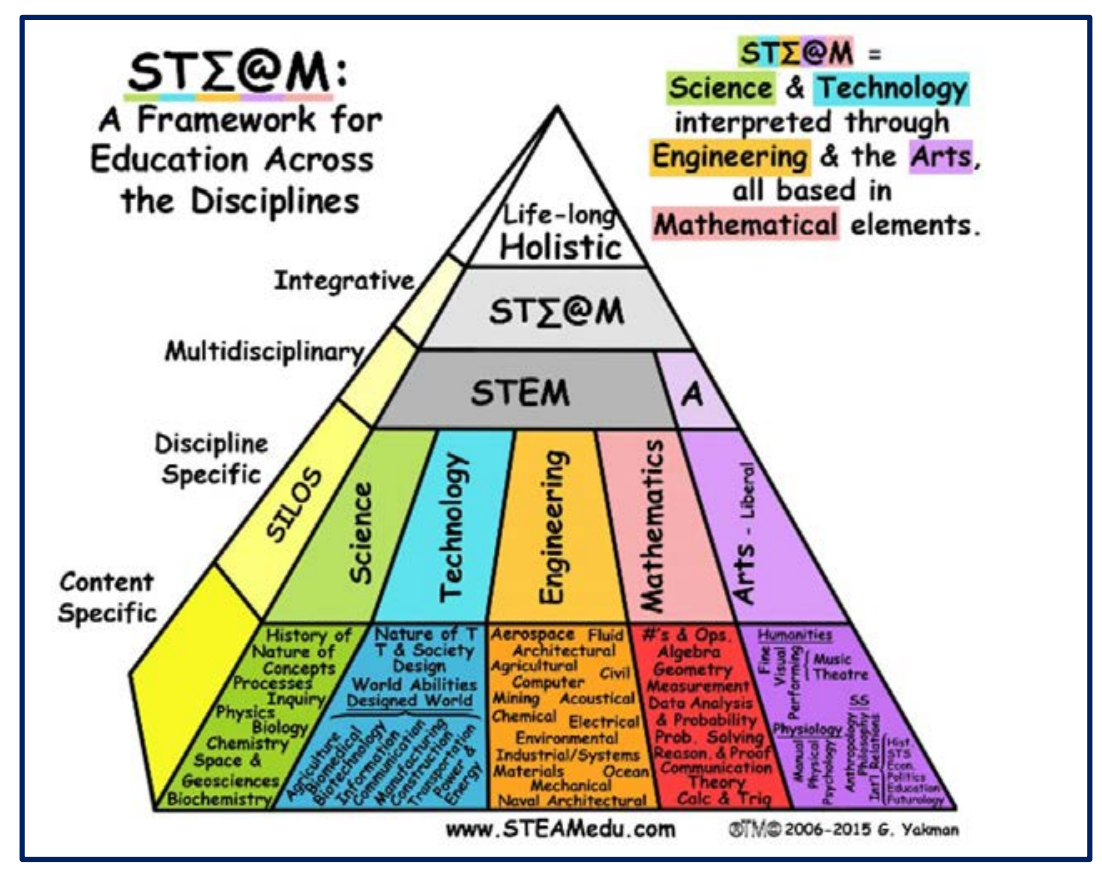


STEAM is becoming increasingly important in ICT-related education and awareness. For example, recently published research discussed the combined use of robots and theatre for STEAM education across the science, art, and education communities (Barnes et al, 2020), whereas Song (2020) describes developing STEAM game content for infant learning. Finally, Ong et al (2020) investigate the effects of creative drama on situational interest, career interest, and science-related attitudes of science majors and non-science majors. It has been argued that computing is by everyone for everyone. Therefore, the ethical conduct of us all influences the acceptability of ICT and we all have the responsibility to challenge the unethical elements in ICT from inception through to implementation and use. Clearly, some more than others will have greater in-depth knowledge and experience of different facets. However, it is the population as a whole which has a complete view. This will include (by way of illustration) the hesitant user of a computerised public service who is the victim of poor system design as well as the junior software engineer who is bullied into unethical yet commercially valuable action. ICT ethics education and awareness must provide the tools and confidence to enable everyone to act responsibly and ethically.

The ICT ethics framework must cater for educational requirements of all. This is a paradigm shift. Yakman (2019) explains that " $A$ " in STEAM represents the Liberal Arts which "include the ethics, ideals and emotional and physical expression grouped into overlapping categories of Humanities, Physiology and Social Studies (SS). In this way, STEAM formally adds in the subject area 'silos' of Language Arts, Social Studies, Music, Fine Arts, and PE." STEAM therefore appears to offer the basis of an ICT ethics framework. This author has been involved in ICT ethics education since 1994. This experience has led to the conclusion that for ICT ethics education programmes to succeed in making a difference there has to be persistent high visibility of these programmes and associated content. Ethics and Responsibility are the keywords. If STEAM is to be used it should be done so in an explicit ethics and responsibility landscape. Therefore to ensure ongoing visibility it could become STEAM-ER which would provide the fuel, impetus and environment to ensure that actions and outcomes in the technological world are more likely to be societally positive rather than societally negative.

Consider this example of how a STEAM-ER ICT ethics activity might work in practice. The example involves the poetry avenue discussed earlier. A cross-curricular project could be established for 11-18 year olds. The preparatory work, in various classes and activities, would focus on the uses and challenges of ICT in various settings. Poetry writing would also be covered both implicitly and explicitly. The culmination of this project would be a poetry writing exercise where pupils would be encouraged to consider the positive and negative effects of ICT, choosing a particular theme to be the subject of a poem. All poems would then be displayed in a public exhibition with pupils having the opportunity to engage with visitors to discuss their work. Those benefitting from this project would include: staff through positive interdisciplinary work relating to ICT ethics; pupils through increased understanding of the social impact issues which surround ICT, as well as practising a range of communication skills; and the general public through increased implicit understanding of ICT ethics.

The STEAM-ER proposal parallels the Responsible Research and Innovation (RRI) advances in recent years. For example, Stahl and Coeckelbergh (2016) argue that traditional approaches to ethics and risk analysis need to be modified to include reflection, dialogue and experiment which explicitly links to innovation practices and contexts of use. STEAM-ER offers a new approach to ICT ethics education which embraces a spectrum of disciplines in an integrated fashion. It could herald the rebirth of ICT ethics education and awareness which aligns more appropriately with a technologically-dependant world of the present and the future. 


\section{CONCLUSION}

This paper has discussed the current shortcoming in ICT ethics education because of the ongoing focus on ICT students who aspire to enter the profession. Four new avenues, by way of illustration, have been outlined which offer novel informal and formal educational experiences. The ICT ethics education framework has been outlined which embraces people of all ages and all walks of life. It is time to start a revolution in your head which will culminate in ethical computing by everyone for everyone. We have to accept and adjust to the fact that we are all technologist to a lesser or greater degree. How we educate our future generations must reflect this change to ensure ICT is societally beneficial. This paper attempts to act as a catalyst for a much-needed paradigm shift in our thinking and application of ICT ethics education, one which heralds a rebirth.

\section{REFERENCES}

Aiken, R. M. (1983). Reflections on teaching computer ethics. ACM SIGCSE Bulletin, 15(3), 8-12.

Anon (1980). How to enjoy a poem. In Cook, C. (Ed.) (1980). Pears Cyclopaedia. 89th edition, Book Club Associates, London. M3.

Barnes, J., FakhrHosseini, S.M., Vasey, E., Park, C.H. \& Jeon, M. (2020). Child-Robot Theater: Engaging Elementary Students in Informal STEAM Education Using Robots. IEEE Pervasive Computing, 19(1), 10-21.

Brown, J. R. \& Fehige, Y. (2014). Thought Experiments. In Zalta, E. N. (Ed.) (2017) The Stanford Encyclopedia of Philosophy (Summer 2017 Edition). Retrieved from https://plato.stanford.edu/entries/thought-experiment/

Bynum, T. W. \& Rogerson,S. (Eds.) (2004). Computer ethics and professional responsibility. Blackwell Publishing.

Burton, E., Goldsmith, J. \& Mattei, N. (2018). How to teach computer ethics through science fiction. Communications of the ACM, 61(8), 54-64.

Dalton, S. (2017). What are oral histories and why are they important? 9 August. Retrieved from https://womenslibrary.org.uk/2017/08/09/what-are-oral-histories-and-why-are-they-important/

Dubcovsky, A. (2014). To understand science, study history. Chronicle of Higher Education, 60(24). Retrieved from https://www.chronicle.com/article/To-Understand-Science-Study/144947

Gazi, A. \& Nakou, I. (2015). Oral history in museums and education: Where do we stand today. Museumedu, 2(Nov), 13-30.

Graham, J. (2019). WWDC 2019: Meet Apple's youngest app developer, Ayush. USA Today, 5 June.

Grosz, B. J., Grant, D. G., Vredenburgh, K., Behrends, J., Hu, L., Simmons, A. \& Waldo, J. (2019). Embedded EthiCS: integrating ethics across CS education. Communications of the ACM, 62(8), 5461.

Johnson, D. G. (1985). Computer ethics. Englewood Cliffs (NJ).

Johnson, D. G. (1997). Ethics online. Communications of the ACM, 40(1), 60-65.

Kuhn, T. (1962). The structure of scientific revolutions. University of Chicago Press. Chicago.

Martin, C. D., Huff, C., Gotterbarn, D. \& Miller, K. (1996). Implementing a tenth strand in the CS curriculum. Communications of the ACM, 39(12), 75-84. 
Miller, K. (1988). Integrating computer ethics into the computer science curriculum. Computer Science Education, 1(1), 37-52.

Nadel, L. \& Wiener, H. (1977). Would you sell a computer to Hitler. Computer Decisions, 28, .22-27.

Ong, K. J., Chou, Y. C., Yang, D. Y. and Lin, C. C. (2020). Creative Drama in Science Education: The Effects on Situational Interest, Career Interest, and Science-Related Attitudes of Science Majors and NonScience Majors. EURASIA Journal of Mathematics, Science and Technology Education, 16, 4-21.

Param, S. (2018). Tanmay Bakshi: The Youngest IBM Watson Developer in the World. TechGig, 5 June.

Pecorino, P. A. \& Maner, W. (1985). A proposal for a course on computer ethics. Metaphilosophy, 16(4), 327-337.

Porter, M. E. \& Millar, V. E. (1985). How information gives you competitive advantage. Harvard Business Review. 63(4), 149-160.

Porter, M. E. (1985). Competitive advantage: creating and sustaining superior performance. The Free Press, New York.

Rogerson, S. (2006). ETHIcol - A lesson from Auschwitz. IMIS Journal. Vol 16(2).

Rogerson, S. (2015). The ETHICOMP Odyssey: 1995 to 2015. Self-published on www.researchgate.net, 12 September DOI: 10.13140/RG.2.1.2660.1444.

Rogerson, S. (2017). The data shadow. ACM SIGCAS Computers and Society, 47(1), 8-11.

Rogerson, S. (2018). Towards a Chronological Taxonomy of Tourism Technology: an Ethical Perspective. ETHICOMP 2018.

Rogerson, S. (2019a). Computing by everyone for everyone. Journal of Information, Communication and Ethics in Society. 17(4), 373-374. Translated into Japanese for inclusion in Murata, K. and Orito, $Y$ (Eds.) Introduction to information ethics. Minerva Shobo, Kyoto, forthcoming.

Rogerson, S. (2019b). Machine - the final chapter. posted on PoetrySoup. 2 October. Retrieved from http://www.poetrysoup.com/poem/machine_the_final_chapter_1185554

Rogerson, S. (2020a). The dangers of dual use technology: a thought experiment exposé. In preparation.

Rogerson, S. (2020b). Poetical potentials: the value of poems in social impact education. ACM Inroads, 11(1), 30-32.

Rule, A. C., Carnicelli, L. A. \& Kane, S. S. (2004).Using poetry to teach about minerals in earth science class. Journal of Geoscience Education, 52(1), 10-14.

Song, M. Y. (2020). Design and Implementation of STEAM Game Contents for infant Learning Education using Gyroscope Sensor. Journal of the Korea Society of Computer and Information, 25(1), 93-99.

Stahl, B. C., \& Coeckelbergh, M. (2016). Ethics of healthcare robotics: Towards responsible research and innovation. Robotics and Autonomous Systems, 86, 152-161.

Trumbull, C. (2003). An Analysis of Haiku in 12-dimensional Space. Paper for HSA_Meeting.

United Nations (1948). Convention on the Prevention and Punishment of the Crime of Genocide, 9 December.

Watson, A. D. \& Watson, G. H. (2013). Transitioning STEM to STEAM: Reformation of engineering education. Journal for Quality and Participation, 36(3), 1-5. 
Williams, J. (2011). STEM education: Proceed with caution. Design and Technology Education: An International Journal, 16(1), 26-35.

Yakman, G., 2008, February. STEAM education: An overview of creating a model of integrative education. In Pupils' Attitudes Towards Technology (PATT-19) Conference: Research on Technology, Innovation, Design \& Engineering Teaching, Salt Lake City, Utah, USA.

Yakman, G. (2019) STEAM- An Educational Framework to Relate Things To Each Other And Reality. K12Digest, December 12.

Note: This is a revision of the original paper to reflect the feedback provided by STEAM Education which is gratefully accepted. STEAM Education is a registered trademark. 